EXTENDED REPORT

\title{
A comparison of four methods of tonometry: method agreement and interobserver variability
}

\author{
P-A Tonnu, T Ho, K Sharma, E White, C Bunce, D Garway-Heath
}

Br J Ophthalmol 2005;89:847-850. doi: 10.1136/bjo.2004.056614

See end of article for authors' affiliations

.....................

Correspondence to: D F Garway-Heath, MD, FRCOphth, Glaucoma Research Unit, Moorfields Eye Hospital, London ECIV 2PD, UK; david.garway-heath@ moorfields.nhs.uk

Accepted for publication 12 November 2004

\begin{abstract}
Aim: To compare the inter-method agreement in intraocular pressure (IOP) measurements made with four different tonometric methods.

Methods: IOP was measured with the Goldmann applanation tonometer (GAT), Tono-Pen XL, ocular blood flow tonograph (OBF), and Canon TX-10 non-contact tonometer (NCT) in a randomised order in one eye of each of 105 patients with ocular hypertension or glaucoma. Three measurements were made with each method, and by each of two independent GAT observers. GAT interobserver and tonometer inter-method agreement was assessed by the Bland-Altman method. The outcome measures were $95 \%$ limits of agreement for IOP measurements between GAT observers and between tonometric methods, and 95\% confidence intervals for intra-session repeated measurements.

Results: The mean differences (bias) in IOP measurements were $0.4 \mathrm{~mm} \mathrm{Hg}$ between GAT observers, and $0.6 \mathrm{~mm} \mathrm{Hg}, 0.1 \mathrm{~mm} \mathrm{Hg}$, and $0.7 \mathrm{~mm} \mathrm{Hg}$ between GAT and Tono-Pen, OBF, and NCT, respectively. The $95 \%$ limits of agreement were smallest (bias $\pm 2.6 \mathrm{~mm} \mathrm{Hg}$ ) between GAT observers, and larger for agreement between the GAT and the Tono-Pen, OBF, and NCT (bias $\pm 6.7, \pm 5.5$, and $\pm 4.8 \mathrm{~mm} \mathrm{Hg}$, respectively). The OBF and NCT significantly underestimated GAT measurements at lower IOP and overestimated these at higher IOP. The repeatability coefficients for intra-session repeated measurement for each method were $\pm 2.2 \mathrm{~mm} \mathrm{Hg}$ and $\pm 2.5 \mathrm{~mm} \mathrm{Hg}$ for the GAT, $\pm 4.3 \mathrm{~mm} \mathrm{Hg}$ for the Tono-Pen, $\pm 3.7 \mathrm{~mm} \mathrm{Hg}$ for the OBF, and $\pm 3.2 \mathrm{~mm} \mathrm{Hg}$ for the NCT.

Conclusions: There was good interobserver agreement with the GAT and moderate agreement between the NCT and GAT. The differences between the GAT and OBF and between the GAT and Tono-Pen probably preclude the OBF and Tono-Pen from routine clinical use as objective methods to measure IOP in normal adult eyes.
\end{abstract}

ntraocular pressure (IOP) measurement has an important role in case detection and management of primary open angle glaucoma. Ocular hypertension (OHT) is associated with an increased risk of developing glaucoma, ${ }^{1}$ and reducing IOP has been shown to lessen progressive loss of the visual field. ${ }^{2}$ Accurate and precise measurement of IOP is, therefore, fundamental to management of glaucoma.

Applanation tonometry is the method of measuring IOP with instruments that indent or flatten the corneal apex. The Goldmann applanation tonometer (GAT) is regarded as the "gold standard." However, there are other objective instruments such as the Tono-Pen, ocular blood flow tonograph (OBF), and the non-contact tonometers (NCTs). The NCT has the potential advantage that it uses an air puff to indent the cornea, reducing the possible risk of cross infection with agents such as adenovirus and variant Creutzfeld-Jakob disease. ${ }^{34}$ In the United Kingdom, most referrals for suspect glaucoma from the primary care setting (optometry practices) are on the basis of NCT measurements. It is therefore important to determine whether the NCT is sufficiently accurate and precise.

Various studies have compared one or two of these instruments with the GAT, ${ }^{5-12}$ and most studies have not compared inter-tonometer agreement with GAT interobserver agreement (variation in measured IOP arise from both intertonometer and interobserver differences). To our knowledge, a broad comparison of all instruments in the same group of patients has not been published.

This study was designed to assess the relative agreement of four methods of tonometry (GAT, Tono-Pen, OBF, and NCT), and to compare inter-instrument agreement with interobserver agreement of GAT IOP measurements.

\section{MATERIALS AND METHODS}

The study was conducted in the glaucoma research unit at Moorfields Eye Hospital (London, UK). One hundred and five untreated patients attending the ocular hypertension, normal tension glaucoma, or glaucoma primary care clinics participated in the study. The study was approved by the Moorfields Eye Hospital institutional review board.

Examination was conducted on either eye (chosen randomly) of each patient. Eyes were anaesthetised with Benoxinate and fluorescein drops (Moorfields Eye Hospital Pharmacy, London, UK). Measurements (GAT, Tono-Pen, $\mathrm{OBF}$, and NCT) were performed in a randomised order, with a recovery of about 2 minutes between methods. ${ }^{13}$ Three readings were taken with each instrument, and with the GAT three readings were recorded by each of two observers. The mean of the three readings was used for comparison between tonometers. All tonometers were calibrated at the start of the study and all IOP measurements (except for the GAT) were made and recorded by a single observer (P-AT).

CCT was measured with the Altair ultrasonic pachymeter (Optikron 2000, Rome, Italy) after tonometric measurements had been performed.

\section{Goldmann applanation tonometry}

IOP was measured with the Goldmann Applanation Tonometer (Haag-Streit, Bern, Switzerland) by two observers. Observer 1 was a medical student (P-AT) and observer 2 was any one of seven medical staff (four ophthalmologists

Abbreviations: CCT, central corneal thickness; GAT, Goldmann applanation tonometer; IOP, intraocular pressure; NCT, non-contact tonometer; OBF, ocular blood flow; OHT, ocular hypertension 


\begin{tabular}{|c|c|c|c|}
\hline & Mean & SD & Range \\
\hline Age (years) & 64.6 & 13.2 & $23-87$ \\
\hline Sex (\% male) & 50 & & \\
\hline Eye side (\% right) & 52 & & \\
\hline CCT $(\mu \mathrm{m})$ & 546.5 & 39.8 & $436-664$ \\
\hline GAT observer 1 IOP $(\mathrm{mm} \mathrm{Hg})$ & 17.2 & 4.3 & $09-32$ \\
\hline GAT observer 2 IOP $(\mathrm{mm} \mathrm{Hg})$ & 17.6 & 4.9 & $09-35$ \\
\hline Tono-Pen IOP $(\mathrm{mm} \mathrm{Hg})$ & 16.6 & 4.4 & $07-29$ \\
\hline OBF IOP $(\mathrm{mm} \mathrm{Hg})$ & 17.1 & 5.9 & $08-34$ \\
\hline NCT IOP $(\mathrm{mm} \mathrm{Hg})$ & 16.4 & 5.0 & $07-29$ \\
\hline
\end{tabular}

and three ophthalmic technicians). For the majority of measurements, observer 2 was an ophthalmologist (KS). All observers were trained and validated in tonometry. Measurements were made in a masked fashion: one observer set the dial to a "random 0" (between $5 \mathrm{~mm} \mathrm{Hg}$ and $10 \mathrm{~mm} \mathrm{Hg}$ ); the other observer applanated, turned the dial to obtain the end point without looking at the dial, and the first observer recorded the pressure. The procedure was repeated with the two observers changing roles.

\section{Tono-Pen tonometry}

The Tono-Pen XL (Mentor, Santa Barbara, CA, USA) was calibrated daily. The operator touched the cornea with the pen tip several times until a reading was displayed. Only measurements with a standard error smaller than 5\% were accepted. If successive measurements differed by more than $5 \mathrm{~mm} \mathrm{Hg}$, the procedure was repeated.

\section{Ocular blood flow tonometry}

Measurements with the ocular blood flow tonograph (OBF Labs Ltd, Malmesbury, Wiltshire, UK) were made with the slit lamp mounted probe. A new disposable and calibrated OBF tip was used for each subject. The subject's cornea was applanated for 5-10 seconds while approximately 200 IOP measurements were taken and averaged to give the final digital readout.

\section{Non-contact tonometry}

The Canon TX-10 non-contact tonometer (Canon USA Inc, One Canon Plaza, Lake Success, NY, USA) automatically recorded three IOP readings. Anaesthetic drops were administered to subjects randomised to have NCT first, so that examination conditions were equivalent to those who had other tonometric measurements beforehand.

\section{Statistical analyses}

Analyses were performed in Microsoft Excel 97 SR-2 (Microsoft Corp, Seattle, WA, USA), MedCalc version 7.2.10

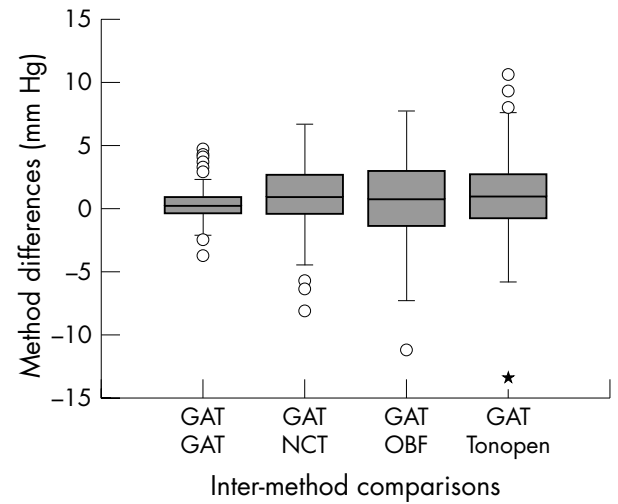

Figure 1 Box plot of inter-method differences. The box represents the interquartile range which contains the $50 \%$ of values. The line across the box indicates the median. The whiskers are lines that extend from the box to the highest and lowest values, excluding outliers. Circles indicate outliers.

(Mariakerke, Belgium), and SPSS for Windows version 10.0.0 (SPSS Inc, Chicago, IL, USA).

For randomisation, each method was assigned a number and a table of random permutations indicated the order of the instruments to be used for subject.

The effect of repeated testing on IOP was assessed for each technique as the difference between the first and third measurements.

Bland-Altman plots were constructed for comparisons between methods and between GAT observers. The systematic difference between methods was termed the "bias" and random differences were quantified by the "limits of agreement." Where there was no relation between intermethod or interobserver differences and IOP magnitude, bias was calculated as the mean difference, and 95\% limits of agreement computed (provided that the differences followed a normal distribution). Where there was a trend of increasing (or decreasing) inter-method/interobserver difference across the range of IOP, regression was conducted and regression based limits of agreement calculated.

Repeatability coefficients were computed as 2.77 times the within subject standard deviation (wsSD) for repeated measurements by the same tonometric method:

$$
w S S D=S D(\text { observation } 1-\text { observation } 2) / \sqrt{2}
$$

\section{RESULTS}

Table 1 lists summary data.

Figure 1 is a summary plot of the median and range of IOP measurement differences between GAT observers and between GAT observer 1 and other tonometers. The median

Table 2 Agreement between tonometry methods: bias and 95\% limits of agreement (or regression based equivalents) ${ }^{*}$ either side of bias

\begin{tabular}{lll}
\hline Tonometry method & Estimated bias & $\begin{array}{l}95 \% \text { limits } \\
\text { of agreement }\end{array}$ \\
\hline Tono-Pen $(\mathrm{mm} \mathrm{Hg})$ & 0.6 & Bias \pm 6.5 \\
Goldmann observer $2(\mathrm{~mm} \mathrm{Hg}) \dagger$ & $1.7-(0.12 \times$ mean) & Bias \pm 2.6 \\
OBF $(\mathrm{mm} \mathrm{Hg}) \dagger$ & $6.0-(0.35 \times$ mean) & Bias \pm 5.4 \\
$\mathrm{NCT}(\mathrm{mm} \mathrm{Hg}) \dagger$ & $3.6-(0.17 \times$ mean) & Bias \pm 4.8 \\
\hline OBF, ocular blood flow; NCT, non-contact tonometer. & \\
${ }^{*} \mathrm{GAT}$ observer 1 was the reference for comparison. \\
+ †Difference between methods related to mean of methods. Bias and 95\% limits of agreement calculated from linear \\
regression of method differences against method mean.
\end{tabular}


Table 3 Estimates (95\% limits of agreement) for differences between GAT observer 1 and GAT observer 2, and between GAT observer 1 and other tonometric methods, at various IOP levels

\begin{tabular}{lllll}
\hline \multicolumn{1}{l}{ IOP $(\mathrm{mm} \mathrm{Hg})$} & & \multicolumn{1}{l}{} \\
\cline { 2 - 5 } & 10 & 15 & 20 & \multicolumn{1}{l}{} \\
\hline Goldmann observer 2 & $0.5(-2.1,3.1)$ & $-0.1(-2.7,2.5)$ & $-0.7(-3.3,1.9)$ & $-1.3(-3.9,1.3)$ \\
OBF & $2.6(-2.9,8.0)$ & $0.8(-4.6,6.3)$ & $-0.9(-6.3,4.6)$ & $-2.6(-8.1,2.8)$ \\
NCT & $1.9(-2.9,6.7)$ & $1(-3.7,5.8)$ & $0.2(-4.6,5.0)$ & $-0.6(-5.4,4.2)$ \\
Tono-Pen & $0.6(-5.9,7.1)$ & $0.6(-5.9,7.1)$ & $0.6(-5.9,7.1)$ & $0.6(-5.9,7.1)$ \\
\hline
\end{tabular}

difference between GAT observers, and between GAT observer 1 and other tonometers was small.

Table 2 lists the bias and 95\% limits of agreement for comparisons between GAT observer 1 and GAT observer 2 and other tonometers. The interobserver differences for the GAT were small in comparison with inter-instrument differences (fig 1 and table 2). The 95\% limits of agreement between other pairs of instrument were all wider than the comparisons with GAT (data not shown).

Observer 2, OBF, and NCT had a slight tendency to overestimate IOP measurements made by observer 1 at high pressures. Table 3 sets out the mean difference and 95\% limits of agreement between instruments at four IOP levels.

The repeatability coefficient of the GAT observers (2.2 $\mathrm{mm} \mathrm{Hg}$ and $2.5 \mathrm{~mm} \mathrm{Hg}$ ) was lower than that of the other tonometers $(3.2 \mathrm{~mm} \mathrm{Hg}, 3.7 \mathrm{~mm} \mathrm{Hg}$, and $4.3 \mathrm{~mm} \mathrm{Hg}$ for the NCT, OBF, and Tono-Pen, respectively). Two readings by the same observer will be within the repeatability coefficient for $95 \%$ of the subjects.

There was no significance difference between the first and third IOP measurements for GAT observer 1, Tono-Pen, or NCT. For GAT observer 2 and the OBF, the first measurement was larger than the third (difference $0.2 \mathrm{~mm} \mathrm{Hg}, \mathrm{p}=0.06$ and $0.6 \mathrm{~mm} \mathrm{Hg}, \mathrm{p}=0.02$, respectively).

\section{DISCUSSION}

In this study, one GAT observer was constant and the other was any one of a number of trained staff (ophthalmologist or ophthalmic technician). This methodology reflects the clinical setting where patients have IOP measured by different personnel at each visit. There was good agreement between the observers (tables 1, 2), with 95\% limits of agreement consistent with previous studies $( \pm 2.2$ to $\pm 3.1 \mathrm{~mm} \mathrm{Hg}$, table 4). ${ }^{11}{ }^{14}$ Agreement was better between the two GAT observers than between the GAT and other tonometers (table 2).

\section{GAT/Tono-Pen comparisons}

The 95\% limits of agreement between the GAT observer 1 and Tono-Pen XL (table 2) were consistent with previous reports (table 4). The average measurement difference (0.6$1.0 \mathrm{~mm} \mathrm{Hg}$, table 1) was small, and there was no tendency for the difference to vary with the level of the IOP (table 2). This is consistent with data reported by Bafa et al and Bandyopadhyay et al (table 4). ${ }^{9}{ }^{15}$ In contrast, a tendency for the Tono-Pen to underestimate IOP at high IOP levels has been reported in studies comparing manometric and TonoPen IOP measurements, ${ }^{16}$ and in those comparing the GAT with the Tono-Pen ${ }^{17}{ }^{18}$ or Tono-Pen XL. ${ }^{10}$

Table 4 Mean difference and 95\% limits of agreement between GAT and other tonometric instruments - summary of findings from this and previous studies. Values $(\mathrm{mm} \mathrm{Hg})$ are given as means $(95 \% \mathrm{Cl})$; a positive mean difference indicates that Goldmann values are higher

\begin{tabular}{|c|c|c|c|c|c|}
\hline Study & $\begin{array}{l}\text { GAT interobserver } \\
\text { differences }\end{array}$ & Tono-Pen & OBF & NCT & NCT type \\
\hline 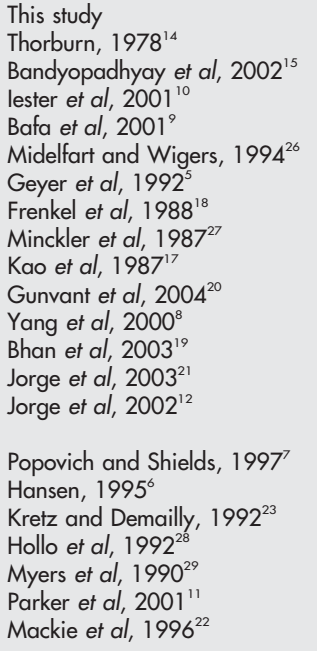 & $\begin{array}{l}-0.4(2.6) \ddagger \\
-0.7(3.1)\end{array}$ & $\begin{array}{l}+0.6(6.5)^{* *} \\
-1.0(4.5)^{* *} \\
+0.2(6.3)^{* *} \dagger \\
-0.6(8.3)^{* *} \\
+2.4(4.6)^{* * *} \\
+3.9(6.5)^{*} \\
+0.8(6.1)^{*} \dagger \\
+1.7(6.1)^{*} \\
-0.5(7.4)^{*} \dagger\end{array}$ & $\begin{array}{l}+0.1(5.4) \ddagger \\
-0.7(7.7) \\
\\
-0.5(6.3) \ddagger \\
+0.26(4.6) \dagger \\
-2.7(6.6) \ddagger\end{array}$ & $\begin{array}{l}+0.7(4.8) \ddagger \\
\end{array}$ & $\begin{array}{l} \\
\\
\text { Reichert AT550 } \\
\text { Reichert AT550 } \\
\text { Reichert XpertP } \\
\text { Reichert XPERT } \\
\text { Reichert XPERT } \\
\text { Reichert XPERT } \\
\text { Reichert XPERT } \\
\text { Reichert XPERT } \\
\text { Keeler Pulsair } 3000 \\
\text { Keeler Pulsair } 2000\end{array}$ \\
\hline
\end{tabular}




\section{GAT/OBF comparisons}

On average, the OBF slightly underestimated IOP measurements by the GAT (table 1 ), in agreement with Yang et al. ${ }^{8}$ In contrast, an overestimation by the OBF was reported by Bafa et al and Bhan et al. ${ }^{19}$ The $95 \%$ limits of agreement were similar to previous findings (table 4).

The OBF underestimated GAT IOP by $2.6 \mathrm{~mm} \mathrm{Hg}$ at $15 \mathrm{~mm} \mathrm{Hg}$ and overestimated GAT IOP by $2.6 \mathrm{~mm} \mathrm{Hg}$ at $25 \mathrm{~mm} \mathrm{Hg}$ (table 3). This finding is in agreement with those of Bhan et al ${ }^{19}$ and Gunvant et al, ${ }^{20}$ but contrary to those of Yang et al. ${ }^{8}$

\section{GAT/NCT comparisons}

There are no reports on the relative performance of Canon TX-10. However, other NCT instruments have been evaluated (table 4).

The 95\% limits of agreement between the GAT and Canon TX-10 correspond well with previous reports for the XPERT NCT, but are not as good as those reported for the Keeler Pulsair 3000, ${ }^{11}$ and the Reichert AT550 in normal ${ }^{12}$ and glaucomatous ${ }^{21}$ eyes (table 4 ).

The NCT had a tendency to overestimate the GAT at high IOP, and underestimate the GAT at low IOP (table 2). Although this effect is not seen in most reports for GAT/NCT comparisons, ${ }^{611} 122122$ Kretz and Demailly ${ }^{23}$ reported a marginal effect in the same direction. Factors such as CCT (evaluated in the companion paper) may contribute to relative IOP overestimation at higher measured IOP levels.

The repeatability coefficient, for two readings by the same observer, was better for the GAT than the other tonometers, with values comparable to those reported by Pandav et al $(2.6 \mathrm{~mm} \mathrm{Hg}){ }^{24}$ The value for the NCT is comparable to Vernon's figure for the Keeler Pulsair 2000 (4.2 $\mathrm{mm} \mathrm{Hg}$ and $3.6 \mathrm{~mm} \mathrm{Hg}$ for right and left eyes, respectively). ${ }^{25}$

The results indicate that repeated readings with the GAT, both within and between observers, are much more reproducible than any of the more automated forms of tonometry. There is moderate inter-instrument agreement between the NCT and GAT and poor agreement between the Tono-Pen and OBF with GAT.

\section{ACKNOWLEDGEMENTS}

The authors thank Haag Streit UK for providing the Canon TX-10 non-contact tonometer.

\section{Authors' affiliations}

P-A Tonnu, T Ho, K Sharma, E White, D Garway-Heath, Glaucoma Research Unit, Moorfields Eye Hospital, London ECIV 2PD, UK C Bunce, Department of Research and Development, Moorfields Eye Hospital, London ECIV 2PD, UK

\section{REFERENCES}

1 Gordon MO, Beiser JA, Brandt JD, et al. The ocular hypertension treatment study: baseline factors that predict the onset of primary open-angle glaucoma. Arch Ophthalmol 2002;120:714-20.
2 Heiil A, Leske MC, Bengtsson B et al. Reduction of intraocular pressure and glaucoma progression: results from the Early Manifest Glaucoma Trial. Arch Ophthalmol 2002;120:1268-79.

3 Walia JS, Chronister CL. Possible iatrogenic transmission of Creutzfeldt-Jakob disease via tonometer tips: a review of the literature. Optometry 2001;72:649-52

4 Desai SP, Sivakumar S, Fryers PT. Evaluation of a disposable prism for applanation tonometry. Eye $2001 ; 15: 279-82$

5 Geyer O, Mayron Y, Loewenstein A, et al. Tono-Pen tonometry in normal and in post-keratoplasty eyes. Br J Ophthalmol 1992;76:538-40.

6 Hansen MK. Clinical comparison of the XPERT non-contact tonometer and the conventional Goldmann applanation tonometer. Acta Ophthalmol Scand 1995;73:176-80

7 Popovich KS, Shields MB. A comparison of intraocular pressure measurements with the XPERT noncontact tonometer and Goldmann applanation tonometry. J Glaucoma 1997;6:44-6.

8 Yang YC, Illango B, Cook A, et al. Intraocular pressure and pulse rate measurements by the $\mathrm{OBF}$ tonograph-comparison to reference instruments. Ophthal Physiol Opt 2000;20:401-407.

9 Bafa M, Lambrinakis I, Dayan M, et al. Clinical comparison of the measurement of the IOP with the ocular blood flow tonometer, the Tonopen XL and the Goldmann applanation tonometer. Acta Ophthalmol Scand 2001;79:15-18.

10 lester M, Mermoud A, Achache F, et al. New Tonopen XL: comparison with the Goldmann tonometer. Eye 2001; 15:52-8.

11 Parker VA, Herrtage J, Sarkies NJ. Clinical comparison of the Keeler Pulsair 3000 with Goldmann applanation tonometry. Br J Ophthalmol $2001: 85: 1303-4$

12 Jorge J, Diaz-Rey JA, Gonzalez-Meijome JM, et al. Clinical performance of the Reichert AT550: a new non-contact tonometer. Ophthalmic Physiol Opt 2002;22:560-4.

13 Recep OF, Hasiripi $H$, Vayisoglu $E$, et al. Accurate time interval in repeated tonometry. Acta Ophthalmol Scand 1998;76:603-5.

14 Thorburn W. The accuracy of clinical applanation tonometry. Acta Ophthalmol (Copenh) 1978;56:1-5.

15 Bandyopadhyay M, Raychaudhuri A, Lahiri SK, et al. Comparison of Goldmann applanation tonometry with the Tonopen for measuring intraocular pressure in a population-based glaucoma survey in rural West Bengal. Ophthalmic Epidemiol 2002;9:215-24.

16 Foster PJ, Wong JS, Wong E, et al. Accuracy of clinical estimates of intraocular pressure in Chinese eyes. Ophthalmology 2000; 107:1816-21

17 Kao SF, Lichter PR, Bergstrom TJ, et al. Clinical comparison of the Oculab Tono-Pen to the Goldmann applanation tonometer. Ophthalmology 1987; $94: 1541-4$

18 Frenkel RE, Hong YJ, Shin DH. Comparison of the Tono-Pen to the Goldmann applanation tonometer. Arch Ophthalmol 1988;106:750-3.

19 Bhan A, Bhargava J, Vernon SA, et al. Repeatability of ocular blood flow pneumotonometry. Ophthalmology 2003;110:1551-4.

20 Gunvant P, Baskaran M, Vijaya L, et al. Effect of corneal parameters on measurements using the pulsatile ocular blood flow tonograph and Goldmann applanation tonometer. Br J Ophthalmol 2004;88:518-22.

21 Jorge J, Gonzalez-Meijome JM, Diaz-Rey JA, et al. Clinical performance of non-contact tonometry by Reichert AT550 in glaucomatous patients. Ophthalmic Physiol Opt 2003;23:503-6.

22 Mackie SW, Jay JL, Ackerley R, et al. Clinical comparison of the Keeler Pulsair 2000 American Optical Mkll and Goldmann applanation tonometers. Ophthalmic Physiol Opt 1996;16:171-7.

23 Kretz G, Demailly P. X-PERT NCT advanced logic tonometer valuation. Int Ophthalmol 1992;16:287-90.

24 Pandav SS, Sharma A, Gupta A, et al. Reliability of proton and goldmann applanation tonometers in normal and postkeratoplasty eyes. Ophthalmology 2002;109:979-84

25 Vernon SA. Reproducibility with the Keeler Pulsair 2000 non-contact tonometer. Br J Ophthalmol 1995;79:554-7.

26 Midelfart A, Wigers A. Clinical comparison of the ProTon and Tono-Pen tonometers with the Goldmann applanation tonometer. Br J Ophthalmol 1994;78:895-8.

27 Minckler DS, Baerveldt G, Hever DK, et al. Clinical evaluation of the Oculab Tono-Pen. Am J Ophthalmol 1987;104:168-73.

28 Hollo G, Follmann P, Pap G. A clinical evaluation of XPERT NCT (Reichert) for glaucoma screening by optometrists. Int Ophthalmol 1992; 16:291-3.

29 Myers KJ, Lalle P, Litwak A, et al. XPERT NCT-a clinical evaluation. J Am Optom Assoc 1990;61:863-9. 